\title{
Editorial
}

\section{Suprapubic Catheterization at Laparotomy}

\author{
C.D. Johnson
}

University Surgical Unit, Southampton General Hospital, Southampton, UK

Urinary drainage by bladder catheterization is a routine part of major abdominal surgery. For the patient, however, this simple procedure may have considerable effects during the postoperative period. Urethral catheters are associated with an increased risk of urinary tract infection (especially in women) [1], bladder spasms, and late urethral stricture formation in men $[2,3]$. The risk of infection is greater after gynaecological surgery [4], and urethral stricture is more likely after long procedures with periods of hypoperfusion, such as cardiac $[2,3]$ or aortic surgery [5]. Suprapubic catheterization should prevent the discomfort associated with a catheter in the urethra, which results from traction of the retaining balloon against the bladder trigone. Suprapubic catheters do not cause urethral strictures and have a lower risk of urinary tract infection because the urethral closure mechanism remains intact. A further attraction of suprapubic catheters is the possibility of testing micturition before the catheter is removed, thereby reducing the risk of retention of urine and the need for re-catheterization.

With all these perceived advantages, why is a suprapubic catheter not the routine choice in all major abdominal surgery? There are some potential difficulties with insertion of the catheter, particularly when the bladder is empty as a result of preoperative dehydration, or when the patient has emptied the bladder shortly before the induction of anaesthesia. Previous abdominal surgery or inflammation with adhesions in the lower abdomen and pelvis may make it difficult to insert the suprapubic catheter safely. If care is not taken in placement of the catheter by an extraperitoneal route, there is a risk of postoperative intraperitoneal leakage of urine from the bladder.

What, then, is the evidence comparing bladder drainage by these two routes? There is considerable evidence from randomized trials that suprapubic catheterization is followed by fewer urinary infections (usually less than $5 \%)$ in the fields of gynaecological $[4,6]$, colorectal $[7,8]$ and major abdominal surgery $[9,10]$. Several authors suggest that patients find this route more comfortable [7, $9,11,12]$. In the light of this evidence in favour of suprapubic catheterization, we compared a trocar-mounted suprapubic catheter and a disposable trocar and cannula for introduction of a standard Foley catheter [11]. That trial confirmed the practicality of the technique (successful insertion in 63 of 70 patients undergoing a variety of abdominal operations) and demonstrated some advantages for the peel-off plastic placement cannula.

A more recent study seems not to confirm the advantages found in earlier trials. Baan et al. [13] found equal infection rates in patients undergoing laparotomy randomized to have either a suprapubic catheter or urethral catheter. However they included in their analysis patients who required urethral catheterization subsequent to removal of the original catheter; in patients who had only a suprapubic catheter the infection rate was $5 \%$ compared with $12.5 \%$ with a urethral catheter.

\section{KARGER}

Fax +41613061234 E-Mail karger@karger.ch www.karger.com (c) 2006 S. Karger AG, Basel

0253-4886/06/0236-0281\$23.50/0

Accessible online at:

www.karger.com/dsu
C.D. Johnson

University Surgical Unit, F Level Centre Block (816)

Southampton General Hospital

Southampton SO16 6YD (UK)

Tel. +44238079 6146, Fax +44238079 4020, E-Mail c.d.johnson@soton.ac.uk 
Baan et al. [13] also looked carefully at symptoms reported by the patients while the catheter was present. Leakage of urine from the urethra occurred in 6\% (suprapubic group) and $10 \%$ (urethral group), and a false urge to empty the bladder in 31 and $45 \%$, respectively. This has not been noted in other studies. However, in this study the catheter was sutured to the abdominal skin, which may explain the rather high rate of false urge and leakage observed in the suprapubic group. Fixation of the catheter in this way can lead to a longer segment of catheter in the bladder, and consequently the possibility of irritation of the trigone. The usual technique of suprapubic catheterization is to inflate the balloon and to rely on this for retention of the catheter in the bladder. In this way the catheter remains high in the bladder with less risk of trigone stimulation.

A recent Cochrane review [14] of bladder drainage showed that re-catheterization was more likely after urethral catheter removal than after a suprapubic catheter (RR 4.72; 95\% CI 2.9-7.6), although this review did not include the only study [13] to demonstrate a higher recatherization rate after suprapubic catherization. However, in that study [13] re-catheterization was mainly required for abdominal complications requiring re-operation. Re-catheterization because of retention of urine would be more common in a patient group containing older men, and the effectiveness of suprapubic drainage for prevention of retention of urine after catheter removal was not tested in this study.

The studies discussed here all suffer to a greater or lesser degree from the tendency to measure what is easy to measure (urinary tract infection, rate of re-catheterization, duration of urinary drainage) and to present inadequate data for features which are difficult to measure (abdominal and bladder discomfort, late urethral stricture, and serious complications such as intraperitoneal urine leakage, which is very rare [12]). Health service costs have not been addressed systematically in any study.

Which route should the abdominal surgeon use to achieve bladder drainage during laparotomy? All but one of the trials noted above have shown better outcome (lower rates of infection and re-catheterization, less patient discomfort) with the suprapubic route. There is no evidence to suggest that urethral catheterization is superior to the suprapubic route, and no reason to believe that this might be the case. Suprapubic catheterization during laparotomy is therefore the route of choice, because of the lower risk of urinary infection if urethral catheterization can be avoided, the abolition of risk of urethral stricture, and because it is almost certainly more comfortable for the patient.

\section{References}

1 Stark RP, Maki DG: Bacteriuria in the catheterized patient. What quantitative level of bacteriuria is relevant? N Engl J Med 1984; 311:560-564.

2 Buchholz NP, Riehmann M, Gasser TC: Absence of urethral strictures with suprapubic urinary drainage during extracorporeal circulation. J Urol 1993;150:337-339.

3 Katz G, Milgalter E, Landau Y, Borman JB: Prevention of urethral strictures following coronary artery bypass graft surgery. Urology 1992;39:433-435.

$\checkmark 4$ Andersen JT, Heisterberg L, Hebjorn S, Petersen K, Stampe Sorensen S, Fischer-Rasmussen W, Molsted Pedersen L, Nielsen NC: Suprapubic versus transurethral bladder drainage after colposuspension/vaginal repair. Acta Obstet Gynecol Scand 1985;64: 139-143.

5 Dinneen MD, Wetter LA, May AR: Urethral strictures and aortic surgery. Suprapubic rather than urethral catheters. Eur J Vasc Surg 1990;4:535-538.
6 Schiotz HA, Malme PA, Tanbo TG: Urinary tract infections and asymptomatic bacteriuria after vaginal plastic surgery. A comparison of suprapubic and transurethral catheters. Acta Obstet Gynecol Scand 1989;68: 453-455.

7 Perrin LC, Penfold C, McLeish A: A prospective randomized controlled trial comparing suprapubic with urethral catheterization in rectal surgery. Aust NZ J Surg 1997;67:554556.

$\checkmark 8$ Ratnaval CD, Renwick P, Farouk R, Monson JR, Lee PW: Suprapubic versus transurethral catheterisation of males undergoing pelvic colorectal surgery. Int J Colorectal Dis 1996; 11:177-179.

9 O'Kelly TJ, Mathew A, Ross S, Munro A: Optimum method for urinary drainage in major abdominal surgery: a prospective randomized trial of suprapubic versus urethral catheterization. Br J Surg 1995;82:13671368.
10 Sethia KK, Selkon JB, Berry AR, Turner CM, Kettlewell MG, Gough MH: Prospective randomized controlled trial of urethral versus suprapubic catheterization. Br J Surg 1987;74:624-625

11 Carty NJ, Yap J, Johnson CD: Prospective randomised trial of two devices for suprapubic catheterisation in general surgical patients. Ann R Coll Surg Engl 1994;76:194196.

12 Klaaborg KE, Kronborg O: Suprapubic bladder drainage in elective colorectal surgery. Dis Colon Rectum 1986;29:260-262.

13 Baan AH, Vermeulen H, van der Meulen J, Bossuyt P, Olszyna D, Gouma DJ: The effect of suprapubic catheterization versus transurethral catheterization after abdominal surgery on urinary tract infection: a randomized controlled trial. Dig Surg 2003;20: 290-295.

14 Niel-Weise BS, van der Broek PJ: Urinary catheter policies for short term bladder drainage in adults. Cochrane Database Syst Rev 2005;3:CD004203. 